\title{
Target (Iris) Lesions of Erythema Multiforme
}

\author{
Surtie F, MBChB, Rehman HU*, FRCPC, FRCPI, FRCP (Glass), FACP \\ Dr HU Rehman, Clinical Associate Professor, Department of Medicine, Regina Qu'Appelle Health Region, Regina General Hospital, 1440 - 14 th Avenue, \\ Regina, SK, S4P 0W5, Canada \\ *Corresponding author: Dry HU Rehman, Clinical Associate Professor, Department of Medicine, Regina Qu'Appelle Health Region, Regina General Hospital, \\ 1440 - 14th Avenue, Regina, SK, S4P 0W5, Canada, Tel: 13065664120; Fax: 13065664150; E-mail: habib31@sasktel.net
}

Received: August 25, 2014; Accepted: August 26, 2014; Published: August 28, 2014

A 21-month old age girl presented with asymptomatic lesions on her right arm of 4 days duration. She denied sore throat, fever and cough and no lesions were found anywhere else including buccal mucosa. She had not taken any medications recently.

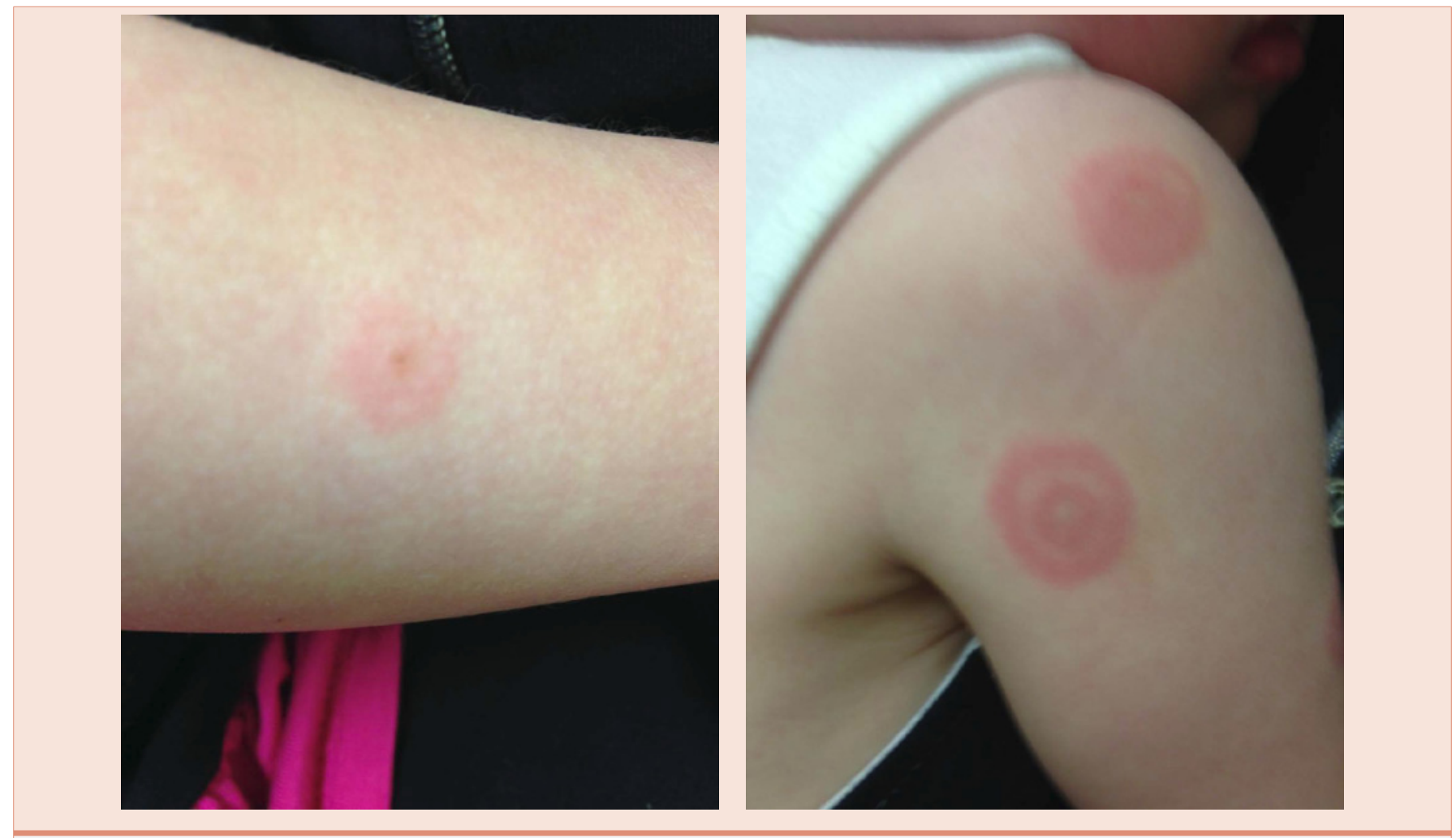

\section{Q 1: What is the diagnosis?}

A: Sharply demarcated, round, red/pink macules target lesions of Erythema Multiforme. The typical target (iris) lesion of EM has a sharp margin, round shape and concentric colour zones.

\section{Q 2: What triggers it?}

A 2: Erythema multiforme (EM) is a hypersensitivity reaction usually triggered by infections and drugs. Herpes simplex is the most common triggering infection. It is self-limiting and resolves without complications. Many drugs have been implicated, most common being barbiturates, non-steroidal anti-inflammatory drugs, penicillins, sulphonamides, phenothiazines and anticonvulsants. 